\title{
Determinantes do Desempenho Institucional: um esboço teórico
}

\author{
Everton Santos, Jucelaine Bitarello e Valdir Pedde
}

\section{Introdução}

Com o processo de redemocratização no Brasil, nas últimas décadas assistimos a um avanço político institucional inegável no país. De maneira geral, as eleições tornaram-se rotineiras e as liberdades políticas de organização e participação têm adquirido importância central. Todavia, nem sempre avanços políticos institucionais significaram melhora efetiva e progressiva das condições de vida dos brasileiros. Convivendo majoritariamente com partidos, parlamento, eleições, os governantes no Brasil têm-se deparado com demanda crescente da sociedade sobre instituições do Estado e suas políticas públicas. Esse é um fenômeno típico de sociedades democráticas, em que as "comportas" que represavam a pressão social sobre o Estado durante tempos pretéritos do autoritarismo foram abertas.

Dessa forma, uma das grandes questões colocadas ao Estado neste início de século é exatamente sobre sua eficiência e capacidade em atender às demandas provenientes da sociedade. Isso nos remete a questionamentos sobre quais são as 
variáveis que podem determinar um desempenho satisfatório das instituições do Estado, incluindo governos nacional, estaduais, municipais e conselhos regionais. Sob que condições políticas institucionais ou mesmo societais podemos ter bom desempenho governamental?

Buscando responder a esses questionamentos, o objetivo deste artigo é construir referencial teórico preliminar que possibilite compreender as razões que determinam o desempenho institucional no caso brasileiro, especialmente no Rio Grande do Sul. Ou seja, os mecanismos que permitem aos governos realizar seus propósitos, como construir estradas, educar crianças e promover o desenvolvimento. Por meio de revisão da bibliografia especializada buscase identificar que fatores podem estar determinando o melhor ou o pior desempenho das instituições políticas, ou, de outra forma, que fatores podem facilitar as ações governamentais de maneira mais ampla além das instituições já existentes? Essas instituições podem mudar a prática dos governos? A eficiência de um governo depende das instituições políticas ou da cultura de seus cidadãos?

As respostas a essas questões são controversas, a bibliografia especializada tem-se dividido basicamente em duas vertentes para dar conta de explicar como um governo pode ter bom desempenho institucional. Há uma vertente teórica chamada institucionalista, em sentido lato, que dá ênfase de maneira geral aos aspectos políticos institucionais do Estado, chamando a atenção para o fato de que um bom desempenho governamental democrático dependeria da arrumação de suas partes formais, de que instituições podem sim influir sobre a sociedade, através da moldura de comportamentos políticos, estimulando ou inibindo atores políticos.
Demonstraremos esse argumento no tópico "Instituições Políticas como Variável Independente", ressaltando especialmente a criação dos municípios e Conselhos Regionais de Desenvolvimento (Coredes) no Rio Grande do Sul como variável que determina o desempenho dos governos.

No segundo tópico, "Cultura Política como Variável Independente", inverteremos o argumento, demonstrando que cultura política é fator determinante do desempenho governamental. Para essa vertente, um bom governo dependeria dos costumes, dos valores da sociedade, de práticas políticas que ajudariam as instituições. Em outras palavras, a qualidade da sociedade seria fundamental para o êxito das instituições.

No terceiro e último tópico, "Instituições e Cultura Política. Um Sinergismo Possível", demonstraremos que instituições políticas que encontram uma sociedade organizada, horizontalizada e detentora de capital social (CS), portanto fértil socialmente (sinergismo entre as duas variáveis), possuem melhores condições de obter êxito em seus propósitos, destacando aqui, grosso modo, diferenças regionais quanto à dotação de CS no estado. Nesse sentido, procuraremos dimensionar teoricamente a dotação de CS no Rio Grande do Sul, bem como seu desenho institucional a partir da criação dos Coredes.

Este artigo justifica-se sob o argumento de que corroborar a hipótese da relação entre CS e desempenho institucional significa demonstrar que o sucesso de reformas políticas está relacionado não somente com a qualidade das leis e instituições e com a capacidade dos governos em implementá-las, mas também com a qualidade do tecido social no qual ela é implantada. Essa hipótese, subvertendo de certa forma o argumento tradicional da virtude pública 
dos governantes, quer chamar a atenção para configurações estruturais que estão na base do sucesso, ou não, do bom desempenho governamental, seu peso na determinação, com fatores institucionais já postos pela estrutura estatal.

\section{Instituições políticas como variável independente}

De maneira geral, podemos dizer que a perspectiva institucionalista como corrente de pensamento tem suas origens remontadas ao século XX nos Estados Unidos, ressaltando como instituições podem determinar o comportamento de atores, dos governos, da economia, ou mesmo do desenvolvimento econômico.

Ocupando a ponta dos debates acadêmicos contemporâneos, o neo-institucionalismo, na perspectiva aberta por Douglass North, vai dar especial acento às instituições, a partir de inflexão da história econômica para estudos mais voltados à evolução de arranjos institucionais, com seu trabalho Sources of Productivity Change in Ocean Shipping, 1600-1850, de 1968. Nessa obra, o autor escreve sobre a evolução da produtividade da indústria de transporte oceânico e constata que as evoluções institucionais foram mais importantes do que inovações tecnológicas para o aumento da produtividade econômica (GALA, 2003)..$^{1}$ Desse ponto em diante, North (2001) entende que o papel das instituições na evolução das sociedades é fator determinante; demonstrando a influência das instituições no desenvolvimento da sociedade, bem como comprovando como o crescimento de longo prazo ou a evolução histórica de uma sociedade é condicionado pela formação e evolução de suas instituições. Nesse contexto, as instituições representam orientações criadas pelos seres humanos, que dão corpo à própria interação humana. Assim sendo, constituem incentivos para intercâmbio, seja político, social ou econômico.

Essas instituições não apenas afetam o desempenho da economia, mas também os diferentes desempenhos econômicos que ao longo do tempo são influenciados pela forma como as próprias instituições evoluem. Assim sendo, elas podem provocar a redução da incerteza, já que

“... as instituições representam orientações criadas pelos seres humanos, que dão corpo à própria interação humana. Assim sendo, constituem incentivos para intercâmbio, seja político, social ou econômico."

proporcionam estrutura à vida diária, definindo e limitando o conjunto de escolhas dos indivíduos. Para tanto, o autor apresenta dois conceitos principais, o conceito de racionalidade e o de instituições. O primeiro é o conceito de racionalidade, que desempenha um papel central na construção de sua dinâmica institucional (sintomaticamente); sua plena utilização rejeita a escolha racional $^{2}$ dos 
neoclássicos que, segundo North (2001), possui axiomas muito rígidos (MuNHOZ, 2006).

Assim, North (2001) propõe uma teoria da racionalidade ampla, que analisa dois aspectos essenciais da conduta humana: a motivação dos indivíduos e a questão da decifração do ambiente. Nesse sentido, o autor defende a construção de modelos mais intrincados para compreender-se a conduta humana dentro de um modelo individual de utilidade esperada, incorporando a ela certos aspectos como o altruísmo, os dogmas, as ideologias e as normas de conduta autoimpostas (Munhoz, 2006). No âmago dessa análise está a impossibilidade de o indivíduo conhecer toda informação necessária para tomada de decisões, do que decorrem questões como a complexidade dos problemas, a falta de capacidade computacional e as realidades mutáveis (GALA, 2003). Ademais, um ponto fundamental da teoria institucionalista desse autor é o papel da ideologia nas sociedades que, ao restringir o comportamento individualista resultante de um cálculo maximizador puro e simples, atua como instituição informal importante para tomada de decisões. A ideologia reduz a incerteza na interação entre pessoas ao estabelecer uma base comum de crenças e regras que permitem trocas econômicas (GALA, 2003). Também a eficiência desempenha papel relevante no marco institucional, configurado na idéia de "instituições eficientes". Nesse sentido, para que a matriz institucional de determinada sociedade seja eficiente, é preciso estabelecer sistema de propriedade bem definido, acompanhado de aparato eficaz de enforcement (MunHOz, 2006). Destarte, qualquer arranjo institucional terá bom desempenho quando for capaz de definir e de garantir direitos de propriedade, que conduzirão organizações $\mathrm{e}$ indivíduos a investir em atividades econômicas produtivas, especialmente na acumulação de capital e de conhecimento (GALA, 2003). Assim sendo, North (2001) observa que os chamados países emergentes e os subdesenvolvidos não se desenvolvem plenamente, em grande parte, pela ineficiência de suas instituições. Em verdade, a incerteza gerada pelo quadro institucional dificulta as transações econômicas entre os indivíduos e impede que os indivíduos conheçam antecipadamente todas as possibilidades decorrentes de suas escolhas, resultando no mau funcionamento das transações econômicas e fazendo com que indivíduos sejam incapazes de atingir soluções ótimas a partir de suas decisões. A própria incerteza eleva os chamados custos de transação, incapacitando a sociedade de estabelecer o cumprimento de contratos de forma eficaz e a baixo custo, constituindo-se na fonte principal da estagnação histórica e do subdesenvolvimento contemporâneo do Terceiro Mundo. É em função da existência dessas incertezas que North (2001) introduz o conceito das instituições. Ao reduzirem os custos de negociação, atenuando o problema da incerteza, as instituições facilitam a coordenação econômica e social. Por exemplo, ao comparar uma economia emergente com uma economia industrial avançada é possível constatar as conseqüências de direitos de propriedade mal definidos ou pouco efetivos. O marco institucional conduzirá até um quadro de insegurança nos direitos de propriedade, resultante do uso de tecnologias que empregam pouco capital fixo e que não significam acordos de longo prazo. Tal situação decorre em economia subdesenvolvida, de matriz institucional que carece de estrutura formal 
capaz de promover mercados eficientes (North, 2001). Em suma, o autor demonstra que instituições fortes e confiáveis são fundamentais para o desenvolvimento e que bastaria aos países emergentes criarem instituições com tais características para alcançarem o desenvolvimento e, conseqüentemente, pode-se deduzir, uma melhora no desempenho de seus governos.

No caso específico do estado do Rio Grande do Sul, torna-se importante essa inflexão teórica para compreensão do seu processo de desenvolvimento. Assim sendo, as configurações institucionais que o estado teve ao longo de sua formação acabaram dando contorno político para o processo de desenvolvimento local inegável.

Como lembra Siedenberg (2003), é a partir de 1804 que os portugueses promoveram a primeira divisão territorial do Rio Grande do Sul (na época, São Pedro do Rio Grande do Sul), criando inicialmente quatro municípios, com a finalidade de ocupar estratégica e militarmente a região: Rio Grande, Porto Alegre, Santo Antônio da Patrulha e Rio Pardo. Assim, ao longo de sua história política tivemos outras subdivisões, criando-se 88 municípios no século XIX e, a partir da segunda metade do século XX, registrando-se crescimento vertiginoso dos municípios, chegando a 496.

Essas emancipações podem ser explicadas por duas razões básicas: pela necessidade que os governos estaduais tinham em garantir e obter maior representatividade na distribuição dos recursos federais; e pelas demandas locais, ou seja, pelo crescimento demográfico, pelas necessidades de melhorias na infra-estrutura urbana, na qualificação dos serviços públicos (Siedenberg, 2003). Nesse sentido, as emancipações geraram situações novas, organizaram as comunidades locais com suas leis orgânicas, aproximaram-se delas, canalizando recursos para a região.

Todavia, no final da década de oitenta tivemos uma "engenharia política" adicional. Com o processo de redemocratização e, conseqüentemente, com reformulações constitucionais tanto em nível federal quanto estadual, e portanto com nova dinamização das relações entre Estado e sociedade no Brasil, houve a criação de legislação favorável à descentralização política regional no estado. A partir de 1994 (no governo Collares), há a criação dos Conselhos de Desenvolvimento Regional (Coredes). ${ }^{3}$ Foram criados com a finalidade de fortalecer a importância econômica do estado no PIB nacional (que estava em decréscimo), induzir diretamente o crescimento econômico, descentralizar as ações políticas e combater as disparidades regionais quanto ao desenvolvimento (SiEDENBERG, 2003). Entretanto, apesar de sucessivos governos não aderirem frontalmente à idéia dos Conselhos num primeiro momento, os CoREDEs resistiram e têmse mostrado ao longo desses 13 anos, segundo especialistas, muito mais como uma instituição capaz de perceber e indicar demandas das diferentes regiões do que propriamente ser capaz de neutralizar as decisões do mercado global, ou mesmo as macropolíticas econômicas de âmbito federal. Dessa forma, esses novos municípios, os Conselhos de Desenvolvimento Regional, ou seja, essas novas configurações institucionais colaboraram, de alguma forma, para a satisfação dos cidadãos com o desempenho das instituições do Estado, auxiliando na organização e aplicação de recursos. Contudo, não são somente essas variáveis institucionais (conselhos, municípios, leis orgânicas) que concorrem para explicar 
o desempenho dos governos e o desenvolvimento regional.

Invertendo o pólo da determinação e da primazia, Robert Putnam (2000), por exemplo, vai argumentar em defesa da cultura política (comunidade cívica) como fator de determinação do desenvolvimento político, social e econômico de uma região, em detrimento dos aspectos institucionais levantados por North (2001). Para Putnam (2000), os aspectos culturais são mais importantes para compreender o desenvolvimento de um país ou de uma região do que as instituições.

\section{Cultura política como variável independente}

Em seu trabalho "Comunidade e Democracia”, Putnam (2000) está preocupado em compreender como alguns dos governos democráticos podem funcionar de maneira satisfatória, uma vez que na contemporaneidade as democracias liberais, "vitoriosas" com o fim do socialismo real, não estão satisfazendo adequadamente as demandas do eleitorado. Então o autor investiga o que é necessário para o bom funcionamento dos governos democráticos, quais são os pressupostos indispensáveis para que a democracia responda aos desafios contemporâneos. Assim, uma das questões centrais que o autor irá investigar é por que alguns governos democráticos têm um bom desempenho institucional e outros não?

Perseguindo essa questão, o autor analisa vinte anos da história política da Itália, demonstrando que esse país apresenta grande diferença regional tanto ao norte, em Seveso, por exemplo, quanto ao Sul, em Pietraportesa. De uma localidade a outra movimenta-se da modernidade capitalista industrial, em alguns casos pós-industrial, ao sul tradicional agrícola. Essas diferenças entre dois extremos necessitaram da ajuda de reformas políticas para resolver seus problemas de administração pública, posto que, na década de 70 , criaram-se diversos governos regionais procurando descentralizar a administração política italiana.

Foram criadas 20 regiões idênticas quanto aos seus poderes; entretanto, os desempenhos dessas regiões foram muito diferentes. Como explicar essa diferença? $\mathrm{O}$ autor procura testar sua hipótese de que são a cultura política e as tradições cívicas que determinam o desenvolvimento socioeconômico de uma região e, nela, o capital social. Para Putnam (2000), CS são práticas sociais, normas e relações de confiança que existem entre cidadãos numa determinada sociedade, bem como sistemas de participação e associação que estimulam a cooperação. Quanto maiores e mais ricas forem as possibilidades associativas numa sociedade, maior será o volume de CS. Dessa forma, a confiança é a expectativa que nasce no meio de uma comunidade de comportamento estável e cooperativo, baseado em normas compartilhadas por esses membros (FUKUYAMA, 1996). A questão central para Putnam (2000) é que a confiança, a cooperação e os espaços de participação social entre o Estado e a sociedade são elementos positivos e essenciais para o bom funcionamento das instituições políticas ${ }^{4}$.

Ou seja, ele toma a cultura política, a variável civismo, como variável independente e o desenvolvimento econômico e o desempenho institucional como variável dependente. Isso significa que "as possibilidades de desenvolvimento socioeconômico de uma região neste século dependeram menos de seu potencial socioeconômico inicial do que de seu potencial cívico" 
(Putnam, 2000, p.166). Mas, como a comunidade cívica pode contribuir para a prosperidade econômica - por meio de que mecanismos? Pode contribuir, por exemplo, pela cooperação horizontal entre empresas nos distritos industriais (PUTNAM, 2000). Isso se reflete em cooperação nos serviços administrativos, na aquisição de matérias-primas, no financiamento e na pesquisa (Putnam, 2000); ou mesmo subcontratando os concorrentes temporariamente. Elas competem, mas na inovação de produtos e na eficiência. Pelo lado da demanda, os cidadãos das comunidades cívicas querem um bom governo e

eles exigem serviços públicos mais eficazes e estão dispostos a agir coletivamente para alcançar seus objetivos comuns. Já os cidadãos das regiões menos cívicas costumam assumir o papel de suplicantes cínicos e alienados. (Putnam, 2000, p.191)

Pelo lado da oferta de serviços do setor público, o governo é favorecido pela infraestrutura social das comunidades cívicas, que acabam colaborando e cooperando com o governo, visando os interesses comuns (Putnam, 2000).

Assim, o autor argumenta, em sua análise das regiões italianas, que se formaram dois sistemas sociais equilibrados na Itália. No norte, um sistema de comunidade cívica, com equilíbrio virtuoso, de cooperação, confiança e reciprocidade. No sul, um sistema não cívico, com equilíbrio vicioso de deserção, desconfiança, omissão e exploração. Aplicando essa perspectiva teórica ao caso do Rio Grande do Sul, Bandeira (2003) estabelece uma diferença regional no estado muito semelhante ao que Putnam (2000) fez na Itália. Como uma primeira aproximação haveria uma diferença entre o "norte colonial", cuja matriz é de imigrantes europeus, com existência de pouca escravidão e predomínio do minifúndio. Em contraste, teríamos no sul do estado uma matriz ibero com o predomínio do latifúndio e o uso extensivo da mão-de-obra escrava.

No que se refere à primeira região, Bandeira (2003) ressalta que essas zonas coloniais de imigração estão dotadas de

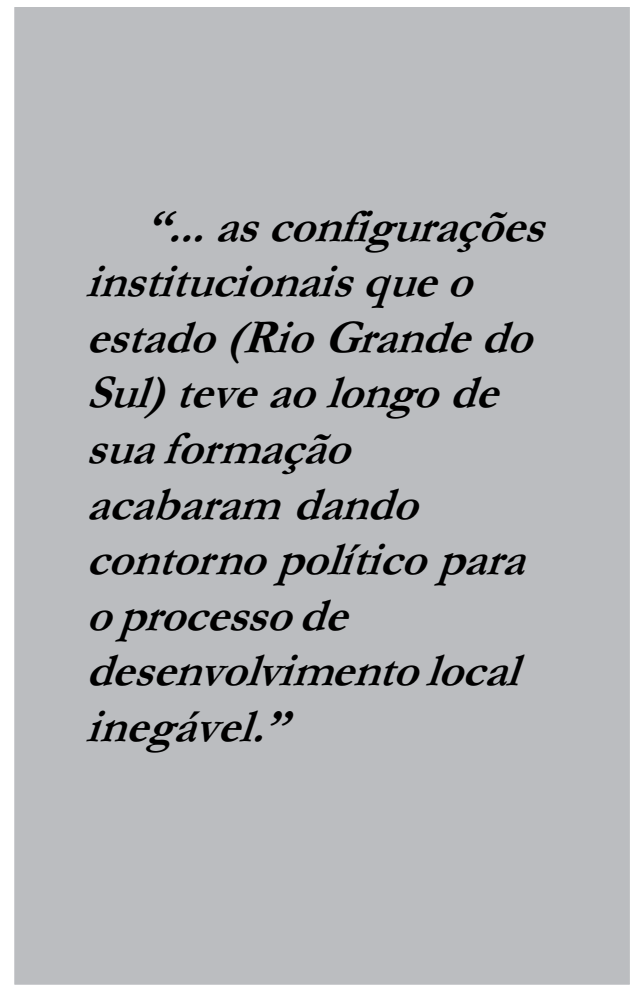

mais CS do que as da região sul. Nas primeiras encontramos uma infinidade de associações recreativas, clubes sociais, sociedades de canto, de atiradores e artísticas, bem como uma intensa vida social colaborativa e cooperativa entre os primeiros colonos que aqui chegaram no século XIX. Nas áreas de colonização italiana, por exemplo, também registra-se essa cooperação: um grupo faz a colheita 
quando um colono está doente; a conservação da estrada é feita por todos, há acordos para a construção do cemitério; a construção da capela foi feita por iniciativa dos pequenos proprietários rurais (De Boni e Costa, 1979 in Bandeira, 2003). Nesse último caso, a vida social desenvolvia-se no entorno da capela, entendida, no seu sentido amplo, como o cemitério, o salão de festas e os campos de esporte. Diferentemente do sul do estado, onde foram os fazendeiros ("os coronéis", que se julgavam donos do trabalho e das posições políticas dos seus empregados) que construíram as capelas, mantidas pelas suas esposas, os agricultores eram convidados para batizados, casamentos, mas nada contribuíam para a organização, construção ou manutenção da capela, ficando a vida social restrita ao entorno da fazenda (De Boni e Costa, 1979 in BANDEIRA, 2003).

Ainda dentro da matriz teórica do CS, Monastério (2003) analisa a qualidade das administrações municipais no estado do Rio Grande do Sul. O que denomina de planalto e serra (utilizando outra divisão territorial, mas referindo-se às zonas de colonização) terá melhores indicadores de qualidade da administração pública, em contraposição às regiões da campanha sul do estado. Em sua análise, na região da campanha há menos leis, informatização, conselhos, gasta-se menos com saúde e educação; ao passo que na serra e no planalto esses indicadores tendem a ser melhores pela dotação de CS.

Nessa perspectiva há forte inclinação patrimonialista e personalista na região da campanha, no sul do estado, que teve tradição ibérica mais forte. Há acentuação singular do afetivo, do irracional, do passional, ou antes uma atrofia das qualidades como ordenadores, disciplinadores e racionalizadores (HolandA 1981, in BANDEIRA, 2003). Somadas a esse traço, há longínquas distâncias entre agrupamentos, escassas instituições de solidariedade social e de cooperação. O que se tem de costume solidário entre vizinhos é proveniente de impulsos da afetividade e da delicadeza moral, não da solidariedade que visa obter utilidade comum (VIANNA, 1999, in BANDEIRA, 2003). ${ }^{5}$

Boschi (1999), comparando duas capitais brasileiras: Belo Horizonte e Salvador, no que diz respeito às experiências de governança, ou seja, à transparência na formulação e eficácia de políticas públicas, argumenta que a principal diferença entre elas está relacionada à existência de CS. No primeiro caso, temos mais estruturas horizontais e CS que ajudam a reduzir as práticas clientelísticas e centralizadas de administração, ao passo que em Salvador essas práticas são mais abundantes e portanto deletérias à administração local, onde temos menos CS e estruturas horizontais de organização.

Para além da divisão dicotômica entre norte e sul no estado do Rio Grande do Sul, incorporamos neste artigo a divisão regional proposta por Bandeira (2003), que divide o estado em três macrorregiões: norte, nordeste e sul. No sul, há base predominantemente agrícola formada pelos vales dos rios Jacuí e Ibicuí, com grandes propriedades rurais, pecuária e lavoura de arroz. Ao norte, compreendendo as áreas do planalto e do Alto Uruguai, há prevalência da pequena e média propriedade, com lavouras mecanizadas do trigo e da soja. No nordeste, há bifurcação. Um nordeste 1, que corresponde à região metropolitana pelo eixo Porto Alegre-Caxias do Sul e por áreas situadas no seu entorno; e um nordeste 2 , correspondendo às áreas mais antigas de 
colonização do estado, a região da serra. As regiões norte e nordeste 2 são marcadas pela imigração européia e dotadas de CS; ao passo que as regiões sul e nordeste 1 seriam as com menos dotações de CS (BANDEIRA, 2003). ${ }^{6}$

\section{Instituições e cultura política: um sinergismo possível}

A proposição da cultura política e, portanto, da importância do CS para explicar o desempenho institucional de uma região (Putnam, 2000; Bandeira, 2001; Monastério, 2003; Boschi, 1999) constitui importante variável para explicar o desenvolvimento econômico e o desempenho das instituições. Contudo, não podem ser compreendidas separadamente, mas devem ser integradas numa perspectiva sinergética que combine instituições e cultura política.

Indubitavelmente, os argumentos tanto de Robert Putnam (2000), na defesa da sociedade cívica e, portanto, da determinação de fatores culturais, quanto de Douglass North (2001), na identificação das instituições como fatores determinantes para o desenvolvimento econômico de uma região, são ao mesmo tempo contundentes e convincentes para compreensão do fenômeno. Entretanto, pode-se citar Przeworski (2005) e argumentar que, embora haja de fato uma contribuição significativa para as Ciências Sociais por parte dessas teorias, a procura de uma determinação primordial para o desenvolvimento e, particularmente, para o desempenho institucional seja um equívoco epistemológico, assim como o que o marxismo cometeu na busca da determinação das condições materiais sobre as instituições políticas.

$\mathrm{Na}$ verdade, a proposição teórica de North (2001) estimula a engenharia institucional na medida em que se pode inserir qualquer instituição em qualquer contexto histórico e teria-se o seu funcionamento como em qualquer outro contexto, assim como o advento da prosperidade (PRZEWORSKI, 2005). Entretanto, não há essa linearidade. As instituições são "endógenas", argumenta Przeworski (20005). Isso significa dizer que

(...) nada pode ser a causa primordial. As instituições não são uma causa mais profunda, podem determinar a provisão de fatores e seus usos, sendo que esses fatores afetam o crescimento e a ulterior prosperidade que, por seu turno, afeta a evolução das instituições” (Przeworski, 2005, p.76).

Quem criou as instituições? Certamente não se criam sozinhas. Além disso, podem ter efeitos diferentes dependendo do contexto. A importação da instituição da estabilidade e do insulamento do funcionário público no Brasil assumiu um papel diferente do que teve essa instituição originalmente na Alemanha. O funcionário público típico alemão é completamente diferente do funcionário típico brasileiro, inclusive no uso que faz dessa prerrogativa.

O autor está chamando a atenção na crítica a North (2001) para o fato de que as instituições são mutuamente interdependentes e evoluem conjuntamente com as dinâmicas societais. Como exemplifica Przeworski (2005), imaginemos a criação de instituições que preservem o poder dos poderosos: essas instituições não são autônomas, mas condicionadas pelo contexto em que estão inseridas e em que foram criadas.

Da mesma forma podemos pensar, na comunidade cívica em Putnam (2000), na determinação do desempenho das 
instituições. Se é a cultura política que determina o grau de desenvolvimento de uma região, então algumas regiões estariam fadadas ao subdesenvolvimento perpetuamente. Mas não, o próprio Putnam (2000) reconhece que a reforma institucional na Itália contemporânea melhorou em geral o desempenho das diferentes regiões, especialmente nas que dispõem de maiores dotações de CS. As instituições não deixam de ter uma importância fundamental para o desenvolvimento, para o próprio desempenho dos governos. Dito isso, deparamo-nos com a dificuldade de estabelecer a "estrutura causal" sobre o desempenho dos governos. Seria a variável 'instituições' ou a variável 'cultura política' que determinaria o desempenho satisfatório dos governos? Seguindo a sugestão de Przeworski (2005), opta-se por compreender essas diferentes variáveis como "circuitos endógenos de mútua determinação e reforçamento". Nessa perspectiva, abrindo mão de buscar identificar o que é endógeno ou exógeno ou o que determina o quê no desempenho dos governos, optamos por identificar apenas seus recíprocos impactos na sociedade, num modelo mais flexível que combine um sinergismo possível entre instituições e cultura política. Aqui, certamente, seguimos Weber, para quem não há monocausalidade para os fenômenos sociais, cabendo à atitude científica mensurar essas impactantes variáveis para o desenvolvimento institucional no Rio Grande do Sul.

\section{Considerações finais}

O objetivo do artigo foi desenhar um referencial teórico que fundamente as discussões sobre as razões que determinam o desempenho satisfatório das instituições políticas, ou seja, os mecanismos que permitem aos governos realizarem seus propósitos. Para tanto, sublinhou-se inicialmente a contribuição teórica do neoinstitucionalismo. Com North (2001), verificou-se que instituições são fundamentais para a configuração social, pois podem provocar redução da incerteza, já que proporcionam uma estrutura segura, definindo e diminuindo incertezas dos indivíduos na hora das escolhas. Assim, instituições eficientes, em que os contratos são cumpridos e os direitos de propriedade são garantidos, podem facilitar as transações econômicas, pois possibilitam aos indivíduos conhecer antecipadamente suas escolhas e investimentos em um ambiente de certezas, levando ao desenvolvimento dessa sociedade. No caso específico do Rio Grande do Sul, a "engenharia institucional" da criação dos municípios, legislações e Coredes constituiu-se em uma iniciativa importante para o processo de desenvolvimento local e institucional no estado.

Num segundo momento, foram pontuadas contribuições da teoria do CS de Putnam (2000), identificando a proposição segundo a qual a cultura política é determinante para definir o desempenho institucional; ou seja, se as dotações de CS em uma determinada sociedade configuram elementos positivos para que os governos realizem suas ações. Os eleitores do norte italiano, mais desenvolvido social e economicamente, mostraram-se ligeiramente mais satisfeitos com seus governantes do que os do sul do país, precisamente pelo fato de que o norte era mais dotado de CS do que o sul. Assim como o Rio Grande do Sul, com suas zonas de colonização alemã e italiana, em contra-posição com o sul, de colonização ibérica, também apresenta características semelhantes às postas por Putnam. 
Num terceiro momento, diante da dificuldade de estabelecermos a "estrutura causal" entre instituições ou cultura política na determinação do desempenho institucional, tratou-se de integrar sinergeticamente as duas variáveis. Partiu-se então da contribuição de Przeworski (2001) sobre "os circuitos endógenos de mútua determinação" para entender que entre essas variáveis há mútua determinação e alimentação. Dessa forma, o que se pode avaliar, tanto na cultura quanto nas instituições, são seus recíprocos impactos sobre o desempenho dos governos, mas não sua primazia.
Essa conclusão remete à reflexão sobre as possibilidades de o Estado tornar-se mais eficiente. $\mathrm{O}$ aumento da eficiência pode dar-se pela reforma nas instituições ou pela melhora das dotações de CS. Esses dois movimentos podem colaborar para a diminuição das desigualdades sociais pela melhora da distribuição de serviços e recursos públicos aos setores mais subalternizados da sociedade gaúcha, caracterizando um círculo virtuoso desejável e necessário na dinâmica relação entre Estado e sociedade, no Rio Grande do Sul e no Brasil.

(Artigo recebido em janeiro de 2008. Versão final em outubro de 2008.)

\section{Notas}

${ }^{1}$ Essa pesquisa resultou no clássico Institutions, Institutional Change and Economic Performance, de 1990, que lhe rendeu o Prêmio Nobel de Economia em 1993.

${ }^{2}$ Estamos nos referindo aqui à teoria da escolha racional (teoria dos Jogos), originalmente elaborada pelo matemático norte-americano John Nash, ganhador do Prêmio Nobel de Economia em 1994 e depois aplicada em diversos campos do conhecimento e em particular às Ciências Sociais.

${ }^{3}$ Atualmente temos um total de 24 Coredes no estado do Rio Grande do Sul.

${ }^{4}$ Não somente para as instituições democráticas, mas também econômicas. Fukuyama (1996) demonstrou que a existência de CS em dada sociedade é fator explicativo do tamanho da estrutura industrial ali existente, bem como do desempenho econômico.

${ }^{5}$ É importante ressaltar que há estudos sobre o sul do estado que não autorizam uma visão estanque e caricata entre norte e sul; no sentido desse último constituir-se em "deserto social", existiriam formas de sociabilidade nas maiores cidades do sul. Na virada do século XX, Bagé é exemplo dessa proliferação associativista, segundo bibliografia especializada.

${ }^{6}$ Contudo, é importante ressaltar que, na região metropolitana do estado, há cidades de imigração alemã forte, como São Leopoldo e Novo Hamburgo.

\section{Referências bibliográficas}

Bandeira, P. 2003. Algumas Hipóteses sobre as Causas das Diferenças Regionais quanto ao Capital Social no Rio Grande do Sul. In: S. CORREA (ed.), Capital Social e Desenvolvimento Regional. Santa Cruz do Sul, Ed. Edunisc, pp.15-59. 
Boschi, R. 1999. Descentralização, Clientelismo e Capital Social na Governança Urbana: Comparando Belo Horizonte e Salvador. Dados - Revista de Ciências Sociais, 42 (4):655-690. GALA, P. 2003. A Teoria Institucional de Douglass North. Revista de Economia Politica, 23(2):89-105.

Monasterio, L. 2003. Medindo o Capital Social: Uma análise das Regiões do Rio Grande do Sul. In: S. CORREA (ed.), Capital Social e Desenvolvimento Regional. Santa Cruz do Sul. Munhoz, C. 2006. Direito, Livre Concorrência e Desenvolvimento. São Paulo, Aduaneiras, 266p. North, D. 2001. Instituciones, cambio institucional y desempeño econômico. México, Fondo de Cultura Econômica, 190p.

PrZEWORSKI, A. 2005. As instituições são a causa primordial do desenvolvimento econômico? Novos Estudos Cebrap, (72):59-77.

Putnam, R. 2000. Comunidade e Democracia. A experiência da Itália Moderna. Rio de Janeiro, Ed. FGV, 257p.

Siedenberg, D. 2004. Condicionantes político-administrativos do desenvolvimento Regional no Rio Grande do Sul - A Experiência dos Coredes. In: M. Wittmann e M. Ramos, Desenvolvimento Regional. Capital Social, Redes e Planejamento. Santa Cruz do Sul, Ed. Edunisc, pp.135-158. 


\section{Resumo - Resumen - Abstract}

\section{Determinantes do Desempenho Institucional: um esboço teórico Everton Santos, Jucelaine Bitarello e Valdir Pedde}

Este artigo tem como objetivo principal construir um ensaio teórico que possibilite compreender as razões que determinam o desempenho satisfatório das instituições do Estado, particularmente no Rio Grande do Sul. Ou seja, compreender os mecanismos que permitem aos governos locais realizar seus propósitos, como construir estradas, educar crianças e promover o desenvolvimento de maneira satisfatória. Para tanto, a partir da revisão da bibliografia especializada, construímos uma episteme que possibilite compreender o desempenho do Estado em suas implicações institucionais formais (neo-institucionalismo) de North (2001), bem como suas implicações com padrões valorativos (capital social) de Putnam (2000). Assim, concluímos que instituições e capital social sinergeticamente aliados podem contribuir para o desempenho satisfatório das instituições do Estado.

Palavras-Chave: Capital Social, Instituições, Desempenho Institucional, Cultura Política.

\section{Determinantes del Desempeño Institucional: un esbozo teórico}

\section{Everton Santos, Jucelaine Bitarello y Valdir Pedde}

Este artículo tiene por objetivo principal construir uma referencia teórica que permita comprender las razones que determinan el desempeño satisfactorio de las instituciones estatales, especialmente en Rio Grande do Sul. O sea, comprender los mecanismos que permiten a los gobiernos locales realizar sus propósitos, como construir carreteras, educar a los niños y promocionar el desarrollo de manera satisfactoria. Para ello, a partir de la revisión de la bibliografía especializada, construimos una episteme que posibilite comprender el desempeño del Estado en sus implicaciones institucionales formales en sí (neo-institucionalismo) de North (2001), así como sus implicaciones con los patrones valorativos (capital social) de Putnam (2000). Por lo tanto, nos encontramos con que las instituciones y el capital social sinergeticamente añadidos pueden contribuir a la correcta ejecución de las instituciones del Estado.

Palabras Clave: Capital Social, Instituciones, Desempeño Institucional, Cultura Política.

\section{Determinants of Institutional Development: a theoretical sketch Everton Santos, Jucelaine Bitarello and Valdir Pedde}

This article has as main objective to build a preliminary theoretical model to make possible to understand the reasons that determine the institutional acting, particularly in Rio Grande do Sul. In other words, to understand the mechanisms that allow to the local governments to accomplish their purposes, how to build highways, to educate the children and to promote the development in a satisfactory way. For so much, starting from the revision of the specialized bibliography, we built an understanding to make possible to understand the acting of the State in their formal institutional implications in itself (neoinstitutionalism), North (2001), as well as, their implications with the patterns values (social capital) that give support the these ("the endogenous circuits of mutual determination"), like this the concept of social capital (CS), it is constituted in the central reference of this article, because, it can allied allied to the political institutions, to favor the governments' acting.

Keywords: Social Capital, Institutions, Institutional Acting, Political Culture. 


\section{Everton Santos}

Doutor em Ciência Política pela UFRGS, coordenador do Mestrado Profissional em Inclusão Social na FEEVALE e líder do Grupo de Pesquisa em Desenvolvimento Regional.

Contato: cintiavvs@gmail.com e evertons@feevale.br

Jucelaine Bitarello

Mestre em Desenvolvimento Regional pela UNISC, professora adjunta no Centro Universitário FEEVALE e pesquisadora do Grupo de Pesquisa em Desenvolvimento Regional.

Contato: jbitarello@feevale.br

Valdir Pedde

Doutor em Antropologia pela UFRGS, atualmente é professor titular no Centro Universitário FEEVALE e pesquisador no Grupo de Pesquisa em Desenvolvimento Regional. Contato: valpe@feevale.br 